\title{
Stattic and metformin inhibit brain tumor initiating cells by reducing STAT3-phosphorylation
}

\author{
Verena Leidgens ${ }^{1}$, Judith Proske ${ }^{1, *}{ }^{,}$Lisa Rauer $^{1, *}{ }^{,}$Sylvia Moeckel ${ }^{1}$, Kathrin Renner ${ }^{2}$, \\ Ulrich Bogdahn ${ }^{1}$, Markus J. Riemenschneider ${ }^{3}$, Martin Proescholdt ${ }^{4}$, Arabel \\ Vollmann-Zwerenz ${ }^{1}$, Peter Hau ${ }^{1}$, Corinna Seliger ${ }^{1}$ \\ ${ }^{1}$ Department of Neurology and Wilhelm Sander-NeuroOncology Unit, University Hospital Regensburg, Regensburg, Germany \\ ${ }^{2}$ Department of Internal Medicine III, University Hospital Regensburg, Regensburg, Germany \\ ${ }^{3}$ Department of Neuropathology, Regensburg University Hospital, Regensburg, Germany \\ ${ }^{4}$ Department of Neurosurgery, University Hospital Regensburg, Regensburg, Germany \\ *These authors have contributed equally to this work
}

Correspondence to: Corinna Seliger, email: corinna.seliger@klinik.uni-regensburg.de

Keywords: glioma, BTIC, STAT3, Stattic, metformin

Received: August 20,2016 Accepted: November 21, $2016 \quad$ Published: December 24, 2016

\section{ABSTRACT}

Glioblastoma (GBM) is the most common and malignant type of primary brain tumor and associated with a devastating prognosis. Signal transducer and activator of transcription number 3 (STAT3) is an important pathogenic factor in GBM and can be specifically inhibited with Stattic. Metformin inhibits GBM cell proliferation and migration. Evidence from other tumor models suggests that metformin inhibits STAT3, but there is no specific data on brain tumor initiating cells (BTICs).

We explored proliferation and migration of 7 BTICs and their differentiated counterparts (TCs) after treatment with Stattic, metformin or the combination thereof. Invasion was measured in situ on organotypic brain slice cultures. Protein expression of phosphorylated and total STAT3, as well as AMPK and MTOR signaling were explored using Western blot. To determine functional relevance of STAT3 inhibition by Stattic and metformin, we performed a stable knock-in of STAT3 in selected BTICs.

Inhibition of STAT3 with Stattic reduced proliferation in all BTICs, but only in 4 out of 7 TCs. Migration and invasion were equally inhibited in BTICs and TCs. Treatment with metformin reduced STAT3-phosphorylation in all investigated BTICs and TCs. Combined treatment with Stattic and metformin led to significant additive effects on BTIC proliferation, but not migration or invasion. No additive effects on TCs could be detected. Stable STAT3 knock-in partly attenuated the effects of Stattic and metformin on BTICs.

In conclusion, metformin was found to inhibit STAT3-phosphorylation in BTICs and TCs. Combined specific and unspecific inhibition of STAT3 might represent a promising new strategy in the treatment of glioblastoma.

\section{INTRODUCTION}

High-grade gliomas, especially glioblastomas (GBM), are highly complex and heterogeneous primary brain tumors, accounting for about $30 \%$ of all tumors of the central nervous system [1]. Glioblastomas are nearly uniformly fatal with median overall survival ranging between 14.6 and 26.3 months in patients treated within clinical studies [2, 3]. Brain tumor initiating cells (BTICs) represent cancer stem-like progenitor cells, which are not only implicated in tumor initiation, but also in recurrence and progression [4-6]. BTICs are characterized by selfrenewal, clonogenicity, pluripotency, and closely resemble the histopathological phenotype of parental tumors after implantation of these cells into athymic mice [6].

Persistent activation of STAT3 (signal transducer and activator of transcription number 3 ) has been detected in many cancers [7], including gliomas, and is correlated 
with poor survival [8]. This was confirmed by correlation of strong expression of STAT3 phosphorylated at Y705 in GBM specimens with a more aggressive phenotype and shorter overall survival [9]. A series of elegant studies has demonstrated an important role of STAT3 in gliomas in vivo and in vitro. Evidence has emerged, that STAT3 is required by BTICs to maintain their stemlike characteristics [10]. RNA interference of STAT3 sufficiently led to growth arrest, inhibited neurosphereformation and could induce apoptosis in BTICs [11]. Hence, STAT3 inhibitors have become a major interest in neuro-oncology. The STAT inhibitor Stattic [12] was shown to selectively inhibit STAT3 [13]. However, it is still unclear whether Stattic binds directly to the phosphorylation site at Y705 or if it acts by altering the conformation of the $\mathrm{SH} 2$ domain, because it binds to Cys687 on the opposite side of the phosphopeptide binding face [13].

Metformin (1,1-dimethylbiguanide hydrochloride) is a biguanide drug mainly prescribed in the treatment of type 2 diabetes [14]. Metformin has also antineoplastic effects and may reduce the risk of certain cancer types in diabetic patients $[15,16]$. Several in vitro studies revealed anti-proliferative effects of metformin on cancer stem cells [17], glioma initiating cells [18, 19], and human GBM lines [20]. Known mechanisms of action of metformin are the inhibition of complex I of the respiratory chain [21], resulting in activation of AMPK (adenosine monophosphate-activated protein kinase) and the inhibition of mTOR (mammalian Target Of Rapamycin) [22]. Interestingly, metformin has been shown to reduce STAT3-phosphorylation in a study investigating triplenegative breast cancer [23]. Similar effects could also be shown in two established GBM lines [24].

The primary aim of our study was to better characterize the effects of STAT3 inhibition on primary BTICs and their differentiated counterparts. In addition to specific STAT3 inhibition with Stattic, we investigated whether metformin inhibits STAT3-phosphorylation in BTICs and whether additive effects can be achieved by combining Stattic with the approved and clinically welltolerated anti-diabetic drug metformin.

\section{RESULTS}

\section{Characteristics of brain tumor initiating cells}

All primary BTICs used here were derived from patients, who had undergone resection of WHO grade IV gliomas at the Neurosurgery Department of the University Hospital Regensburg [19, 25]. Primary cell lines were established and used in low (typically below passage 8) passage numbers to assure maximum resemblance to original tumor cells. $\mathrm{O}^{6}$-methylguanine-DNA methyltransferase (MGMT) methylation status varied in-between the lines, while all lines were isocitrate dehydrogenase 1-(IDH1) wild type in culture. BTIC-13 lost its IDH1 R132H mutation under culture conditions (Table 1). Cells were kept as BTICs under serum free conditions, and after withdrawal of growth factors and addition of $10 \%$ serum to the cell culture medium as differentiated tumor cells (TCs).

\section{Stattic treatment reduces proliferation and migration of BTICs and TCs}

First, we investigated the effects of different doses of Stattic on proliferation (Figure 1) and migration (Figure 2) of BTICs and TCs. Proliferation was assessed after 48 and $96 \mathrm{~h}$ to ensure sufficient proliferation while simultaneously avoiding cell death due to high confluence. Migration was analyzed at $16,24,40$ and $48 \mathrm{~h}$, to provide also early time points $(16,24 \mathrm{~h})$, when migration is not confounded by proliferation. The reduction of proliferation and migration caused by Stattic was dose-dependent and cell linedependent. High doses of Stattic $(10-15 \mu \mathrm{M})$ inhibited proliferation in all BTIC lines and in 4 out of 7 respective TC lines significantly and in two other lines noticeably (Figure 1 and Supplementary Figure 1). Protein expression of pSTAT3 at Y705 was dose-dependently reduced after Stattic treatment (24 h), while total STAT3 was not affected, as assessed by Western blot (Figure 1F). When investigating migration at early time points $(24 \mathrm{~h})$, high doses of Stattic restricted migration in 6 out of 7 BTIC lines and in all TC lines (Figure 2 and Supplementary Figure 2). When comparing sensitivity of BTICs and TCs, BTICs were significantly more sensitive to Stattic than TCs regarding proliferation (Figure 1E), but also differed according to their basal proliferative capacity, which is observable when comparing the DMSO controls. Migration did not differ between BTICs and TCs (Figure 2E).

\section{STAT3-overexpression enhances proliferation and migration}

We assessed effects of STAT3-overexpression on proliferation, migration, and Stattic sensitivity in exemplary cell lines (BTIC-8 and -13). We chose BTIC8 and -13 due to their good response to Stattic as wild type cells, which unmasks a reduction of inhibitory effects more easily than in cells that already respond less in the wild type state. Markedly increased levels of STAT3 were confirmed via qRT-PCR (Figure 3A, 3B) and Western blot (Figure 3C) upon transfection with the STAT3 construct. Stattic treatment led to weaker effects on STAT3-phosphorylation in STAT3-overexpressing cells (Supplementary Figure 3). Upon STAT3-overexpression, BTIC-8 revealed significantly increased proliferation after 96 h (Figure 3D). Sensitivity to Stattic appeared slightly weaker in both lines for some Stattic concentrations, but the results did not reach statistical significance. Migration was enhanced due to increased STAT3 expression (Figure 3F, 3G), but sensitivity to Stattic did not differ 
Table 1: Patient characteristics

\begin{tabular}{|c|c|c|c|c|c|c|c|}
\hline & Histology & $\begin{array}{c}\text { WHO } \\
\text { Grade }\end{array}$ & MGMT meth. & IDH1 & Age & Gender & OS (months) \\
\hline BTIC-7 & Primary GBM & IV & - & wt & 52 & $\mathrm{f}$ & 16.3 \\
\hline BTIC-8 & Primary GBM & IV & - & wt & 52 & $\mathrm{f}$ & 4.0 \\
\hline BTIC-10 & Primary GBM & IV & + & wt & 46 & $\mathrm{~m}$ & 18.8 \\
\hline BTIC-11 & Primary GBM & IV & + & wt & 55 & $\mathrm{~m}$ & 17.5 \\
\hline BTIC-12 & Gliosarcoma & IV & + & wt & 69 & $\mathrm{~m}$ & 16.5 \\
\hline BTIC-13 & Secondary GBM & IV & + & $\mathrm{R} 132 \mathrm{H}$ & 42 & $\mathrm{~m}$ & 8.5 \\
\hline BTIC-18 & Primary GBM & IV & - & wt & 49 & $\mathrm{~m}$ & 20.5 \\
\hline
\end{tabular}

Seven different BTICs and their differentiated counterparts were used for in vitro assays. All BTICs were derived from WHO grade IV gliomas. While MGMT methylation status differed between lines, IDH mutation was negative for all cells in culture (R132H mutation in BTIC-13 was lost under culture conditions).

A

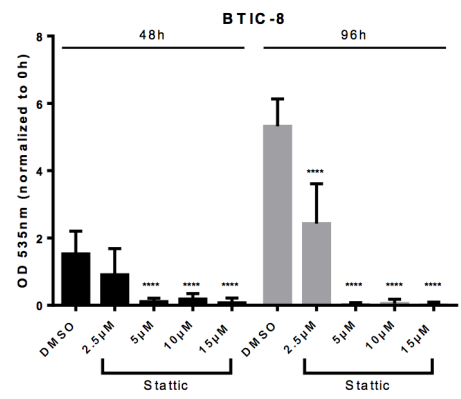

C

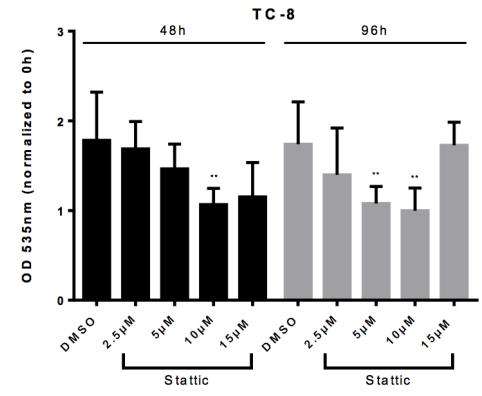

E

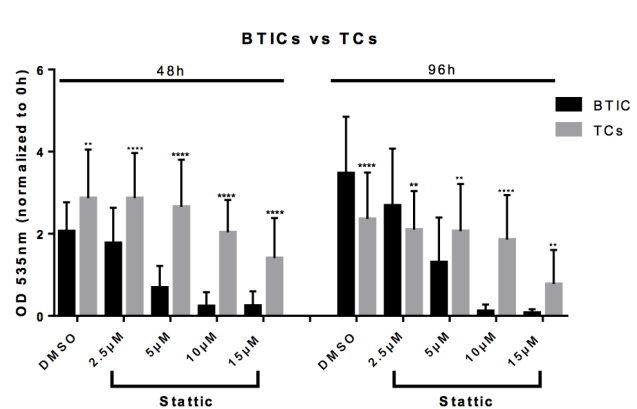

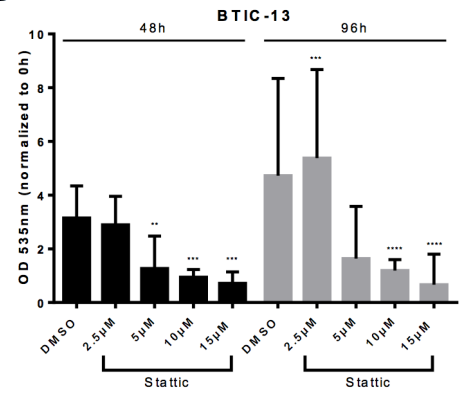

D

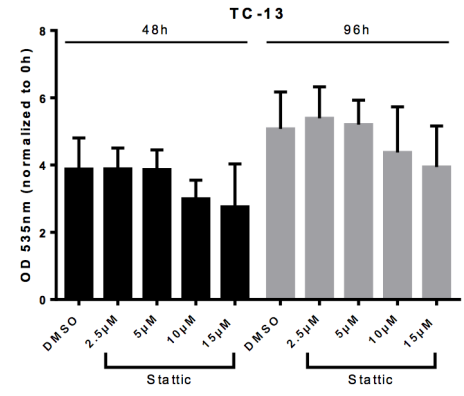

$\mathbf{F}$

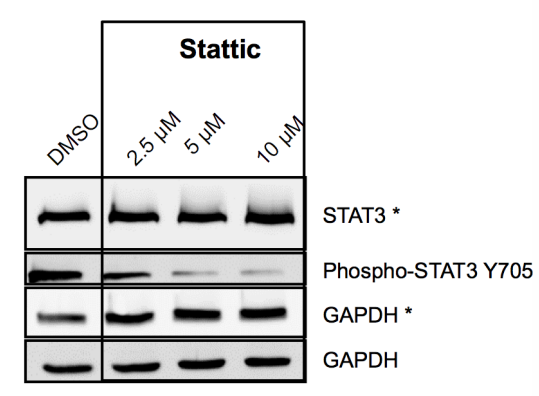

Figure 1: Proliferation is reduced upon Stattic treatment. Exemplary proliferation of BTIC-8 A. and -13 B. and respective TC-8 C. and -13 D. upon Stattic treatment at indicated concentrations $(2.5,5,10,15 \mu \mathrm{M})$. E. Proliferation of BTICs (summarized for BTIC-7, $-8,-10,-11,12,-13,-18$ ) was affected significantly more than that of the respective TCs (summarized for TC-7, -8, -10, -11, 12, -13, -18). F. Stattic treatment $(24 \mathrm{~h})$ reduced phosphorylation of STAT3 as exemplarily shown in Western blot analysis of BTIC-11. Corresponding GAPDH controls are indicated by use or not use of the asterisk. 
substantially between wild type and knock-in (Figure 3F, $3 \mathrm{G})$.

\section{BTIC motility is affected by Stattic in an in situ 3D model}

Spheroids of lentivirally transduced and fluorescence tagged BTIC-8, BTIC-10, BTIC-12 and BTIC-13 were implanted on OBSCs (organotypic brain slice cultures). Migration areas were analyzed over 14 days in vitro $(=\mathrm{div})$ and normalized to 0 -h spheroid expansion areas. Treatment of OBSCs with Stattic $(15 \mu \mathrm{M})$ led to significantly reduced invasion in all investigated BTICs and TCs (Figure 4A-
4D). In BTIC-8 and TC-8 Stattic treatment led to slightly reduced invasion between day 0 and day 7 , but the cells were hardly detected anymore at day 14, indicating cytotoxicity. Exemplary pictures of invading BTIC-13 are shown in Figure 4E. BTICs tended to migrate farther than TCs, but both groups had similar migratory potential after treatment with $15 \mu \mathrm{M}$ Stattic.

\section{Metformin inhibits STAT3-phosphorylation}

Based on the results above and published effects of metformin on BTICs [18, 19], we next investigated STAT3-phosphorylation at Y705 and S727 after
A

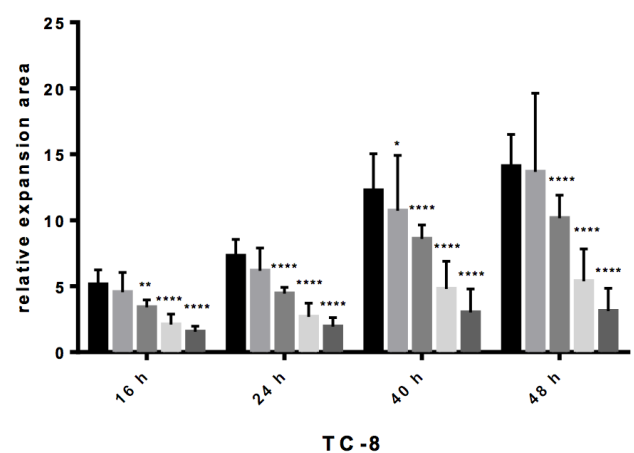

C

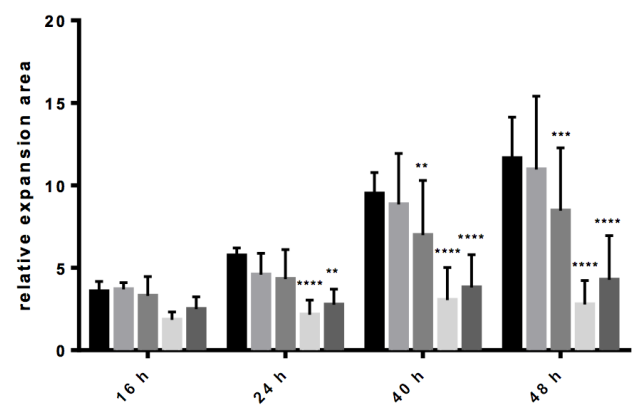

E

B TIC vs TC
B
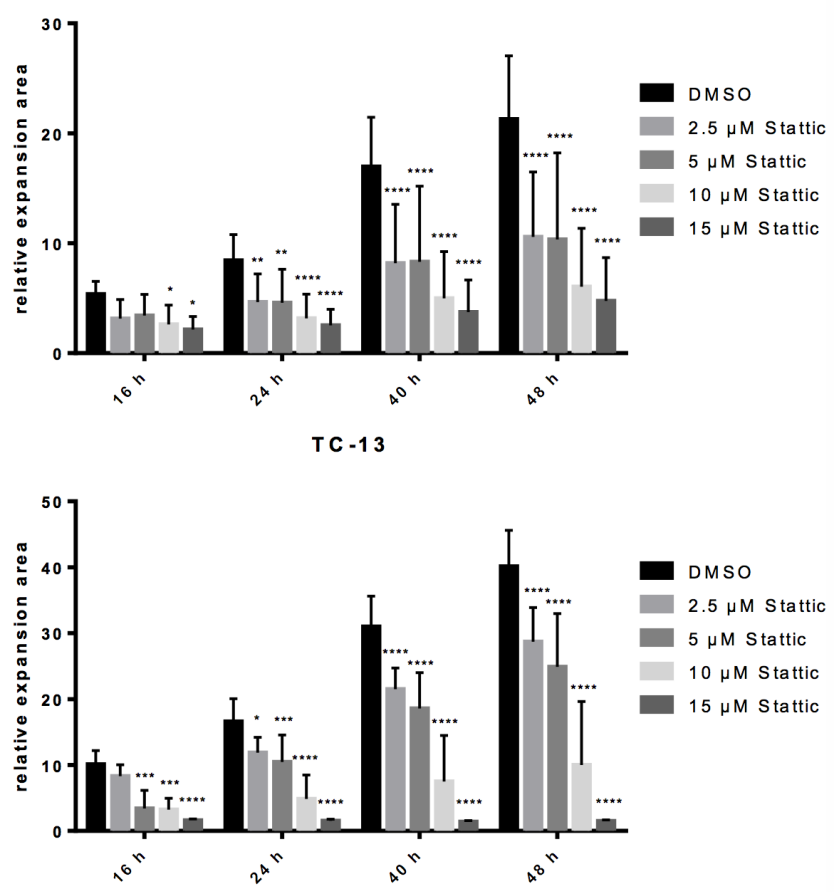

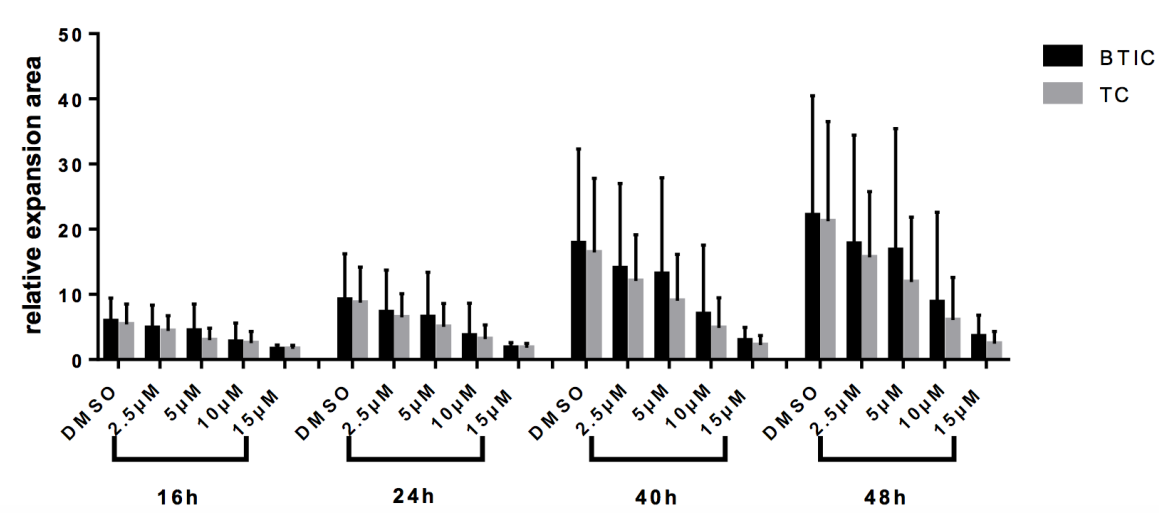

Figure 2: Migration is restricted upon Stattic treatment. Exemplary migration of BTIC-8 A. and -13 B. and respective TC-8 C. and -13 D. upon Stattic treatment at indicated concentrations $(2.5,5,10,15 \mu \mathrm{M})$. E. Migration of BTICs (summarized for BTIC-8, $-11,-13$, -18 ) and respective TCs (summarized for TC-8, $-11,-13,-18$ ) was equally affected. 
treatment with increasing doses of metformin (Figure 5). Following a $48 \mathrm{~h}$ treatment, metformin inhibited STAT3phosphorylation in all investigated BTICs and TCs (Figure 5 and Supplementary Figure 4). Signaling pathways known to be influenced by metformin (activation of AMPK and inhibition of mTOR) are shown as positive control in BTIC-11. STAT3 knock-in opposed (low dose) or weakened (high-dose) the effects of metformin treatment, as shown exemplarily in BTIC-8 (S4D).

\section{Combined treatment with Stattic and metformin increases functional effects}

Based on the influence of metformin on STAT3phosphorylation we investigated the effects of combined treatment with Stattic and metformin on proliferation (Figure 6) and migration (Figure 7) of BTICs and TCs. Low dose combination treatment (1 $\mathrm{mM}$ metformin and $2.5 \mu \mathrm{M}$ Stattic) resulted in strong and additive proliferation inhibition in all BTIC lines (Figure 6 and Supplementary Figure 5). In contrast, no additive effects were observed for TC lines (Figure 6 and Supplementary Figure 5). Compared to single treatment, the combination did not result in enhanced restriction of migration as seen in BTICs as well as TCs (Figure 7 and Supplementary Figure 6). In addition, the combination of metformin and Stattic did not lead to additive effects regarding invasion as investigated in BTIC-8 using the aforementioned OBSC model (Supplementary Figure 7).

\section{DISCUSSION}

For the first time, we were able to demonstrate that metformin in combination with specific STAT3 inhibition by Stattic additively reduced proliferation in a multitude of primary human BTICs. Furthermore, we observed that metformin inhibited phosphorylation of STAT3 in all BTICs and TCs. On the contrary, the combination of Stattic and metformin affected migration of BTICs and TCs to a lower extent in all primary lines. Stable knockin of STAT3 led to a slight attenuation of the observed effects, while proliferation and partly migration was enhanced.

Many studies have been performed to identify and understand aberrant regulation of STAT3 and its impact on proliferation, migration, and invasion. Among those, Bromberg et al. [26] reported that dominant-negative STAT3 abrogated oncogenic transformation, whereas constitutively activated STAT3C [27] mutants induced it. Furthermore, STAT3 was shown to be essential in human glioma cells to maintain their tumor initiating capacity and the ability to invade the normal brain [10]. These findings indicated STAT3 as a promising target for anticancer therapy.

Stattic was used in concentrations ranging from 2.5 to $15 \mu \mathrm{M}$ to reveal minimal dosages required for proliferation and migration restriction in vitro. Although in vitro studies reported cell cytotoxicity even with low Stattic concentrations, in vivo animal studies revealed no
A

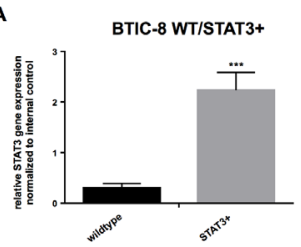

B

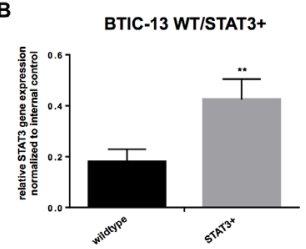

C

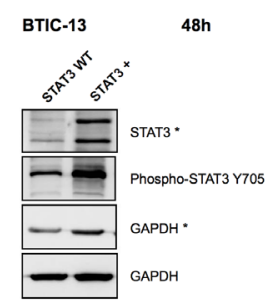

D

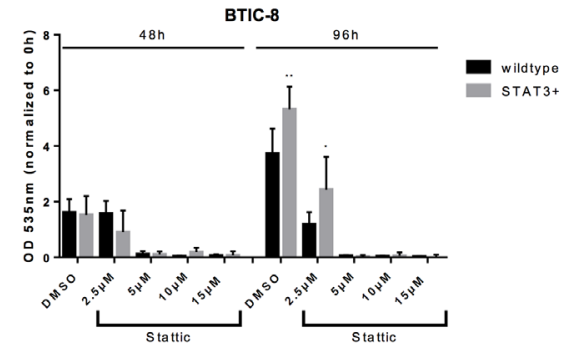

E

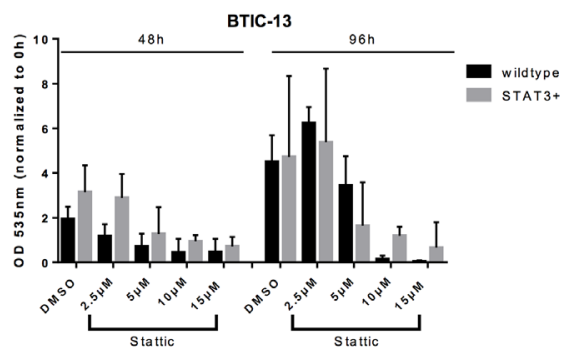

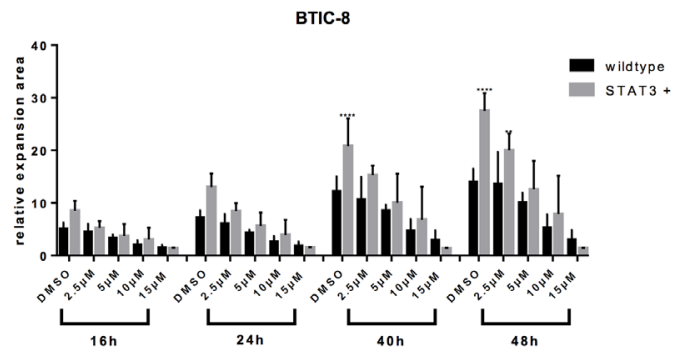

G

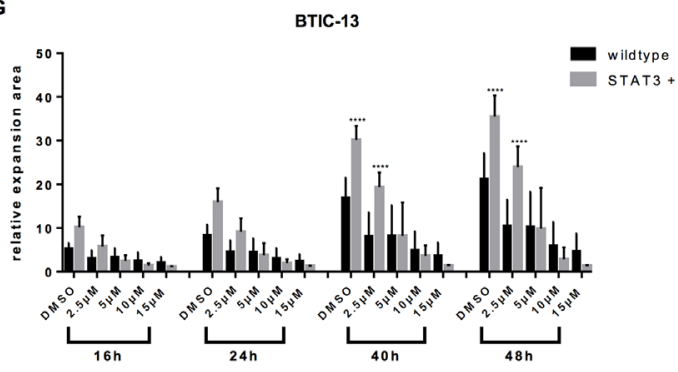

Figure 3: Effects of STAT3-overexpression in BTICs. A, B. STAT3-overexpression was confirmed by qRT-PCR and Western blot C. Corresponding GAPDH controls are indicated by use or not use of the asterisk. D, E. Proliferation of wild type and STAT3overexpressing BTIC-8 and BTIC-13 upon Stattic treatment. F, G. Migration of wild type and STAT3-overexpressing BTIC-8 and BTIC-13 upon Stattic treatment. 

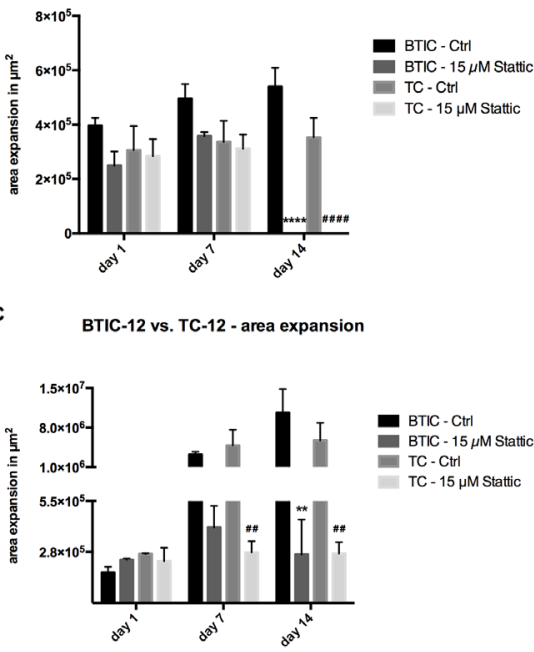

B

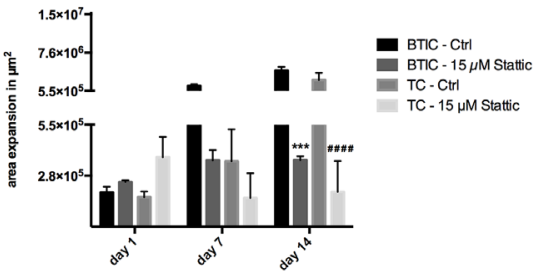

D

BTIC-13 vs. TC-13 - area expansion

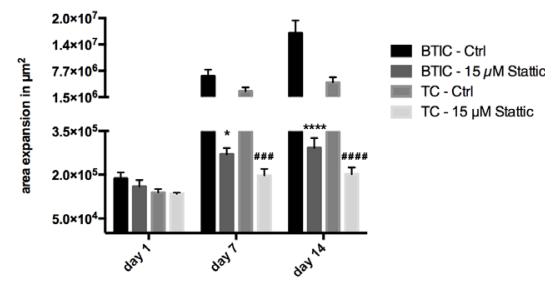

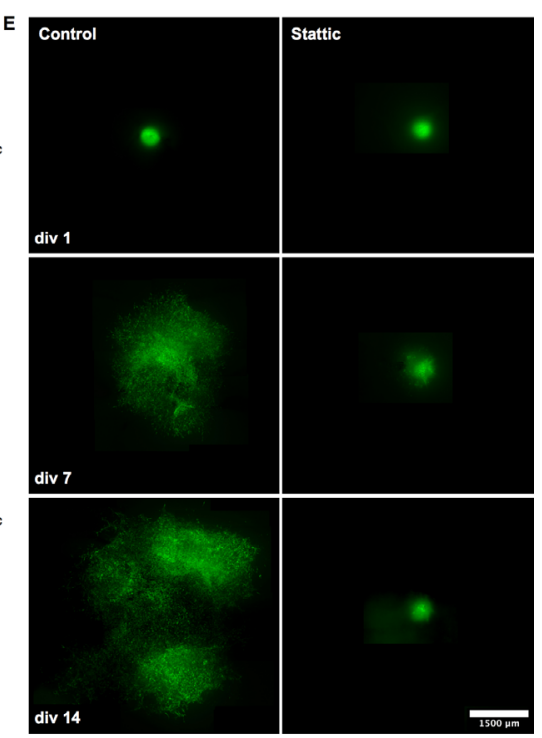

Figure 4: Effects of STAT3 inhibition in BTICs and TCs on OBSCs. A-D. Spheroid expansion area of BTIC-8, $-10,-12$ and -13 and respective TCs on OBSCs with or without treatment with $15 \mu \mathrm{M}$ Stattic every other day. Exemplary pictures of BTIC-13 are shown in $(\mathrm{E})$.

A

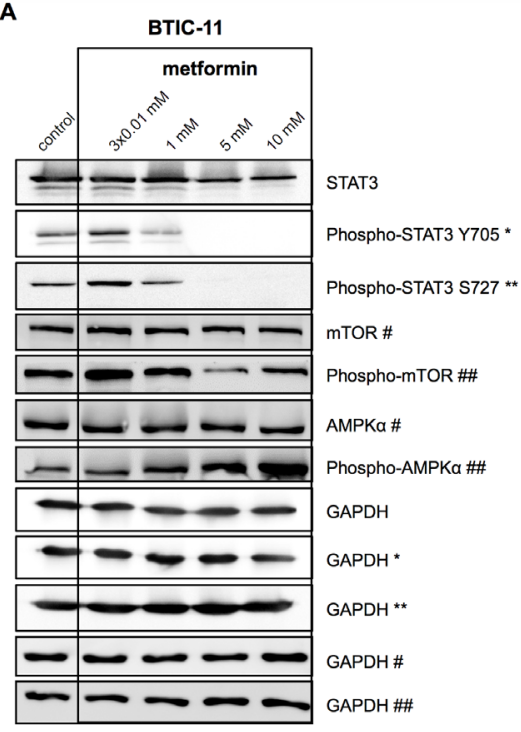

B

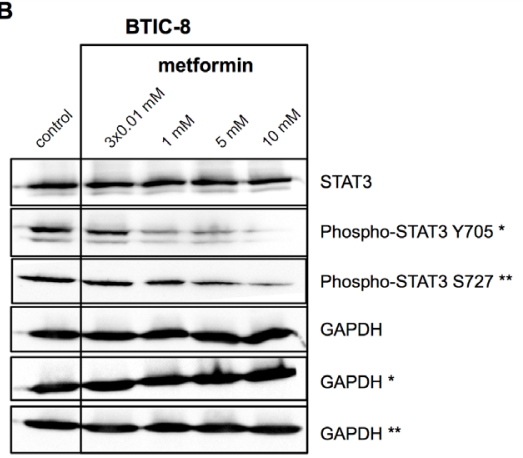

D

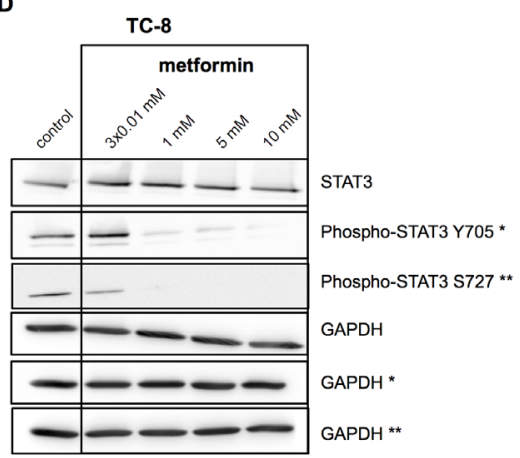

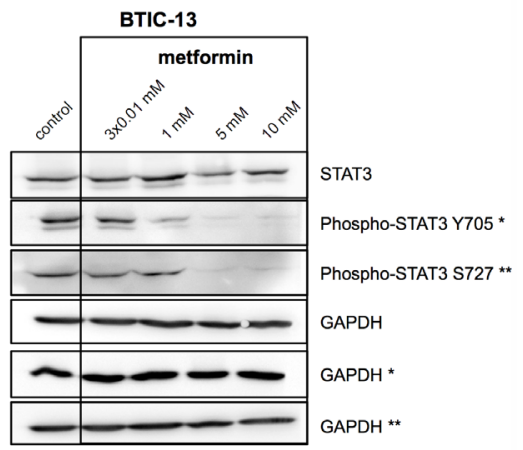

E

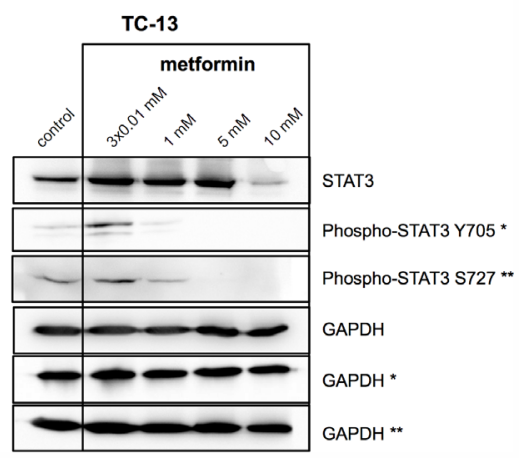

Figure 5: Metformin reduces STAT3-phosphorylation. Western blot analyses of BTIC-11 A., - 8 B. and -13 C. revealed reduced levels of phosphorylated STAT3 at Y705 and S727 after $48 \mathrm{~h}$ of metformin treatment. Activated AMPK and reduced mTOR signaling are displayed as positive controls (A). Similar effects were seen in respective TC- 8 D. and -13 E. Corresponding GAPDH controls are indicated by the same number of asterisks/pounds signs. 
signs of severe side effects using Stattic concentrations distinctly exceeding those used in vitro. In line with this, Lin et al. [28] demonstrated high cell cytotoxicity rates in GBM cell lines in vitro even with low Stattic concentrations $(0.73 \mu \mathrm{M}$ U87 and $0.84 \mu \mathrm{M}$ U251), whereas others administered $3.75 \mathrm{mg} \mathrm{kg}^{-1}$ Stattic [29] or $10 \mathrm{mg} \mathrm{kg}^{-1}$ subcutanously [30] without side effects in their animal models. Missing side effects are likely due to the fact that STAT3 may not be essential for viability of normal cells in adult mammalians [7].

According to the cancer stem cell model, tumor recurrence after initial treatment results from remaining, therapy-resistant cancer stem cells (reviewed in [31]). In our study, substantially lower Stattic concentrations were required to restrict proliferation of BTICs than of TCs, indicating a more important role of STAT3 in BTIC proliferation than in TCs or a higher pharmacological susceptibility. Although therapy-resistance of cancer stem cells is widely assumed, it lacks conclusive experimental evidence [31]. Consequently, it may not be excluded that inhibition of a central transcription factor as STAT3 has profound consequences for those tumor cells, namely BTICs, that contain self-renewal and multilineage differentiation capacity in contrast to more differentiated tumor cells, especially since loss of STAT3 was shown to be lethal in embryonic stem cells [32]. STAT3 was shown to be critically involved in cell survival and cell cycle progression, particularly via induction of c-myc and several cyclins [33], as well as to contribute essentially to maintain the ability to invade the normal brain [10]. It is likely that BTICs depend more on STAT3 for their cell cycle progression, while STAT3 contributes equally to migration and proliferation in differentiated tumor cells. In addition, our BTICs were cultured in Epidermal Growth Factor Receptor (EGFR) enriched culture medium. EGFR is commonly upregulated in glioblastomas [34], and high expression of EGFR leads to Akt-activation through the phosphatidylinositol 3-kinase pathway [35] and increased pSTAT3 expression [36]. It therefore seems plausible, that BTICs respond better to STAT3 inhibition due to enhanced expression of the therapeutic target, which will likely also be the case under physiological conditions in the patient.

Stable knock-in of STAT3 slightly attenuated the effects of Stattic on the functional level and on protein expression, which is most likely explained by the fact, that the overexpressing form is constitutively active. The difference of effects of wildtype and STAT3-
A

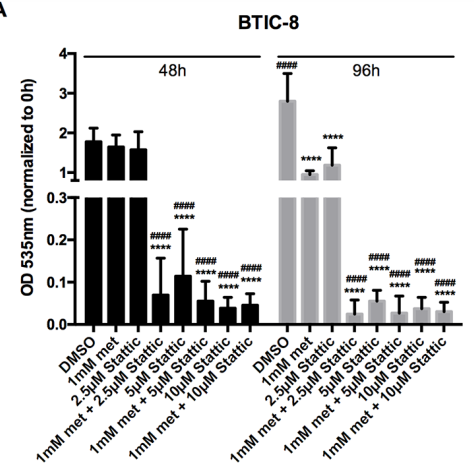

c

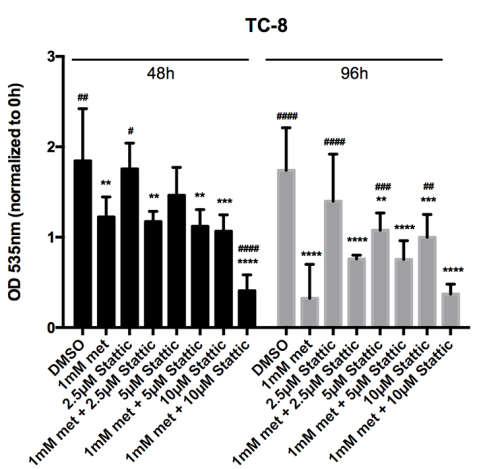

B

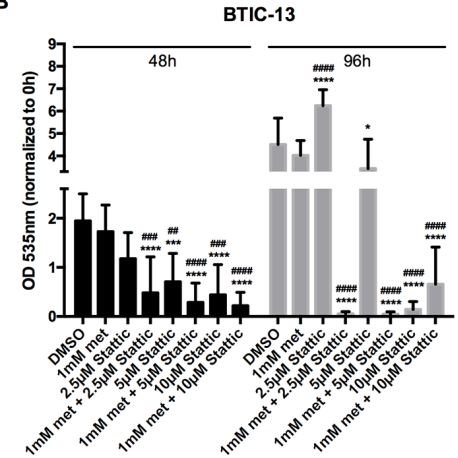

D

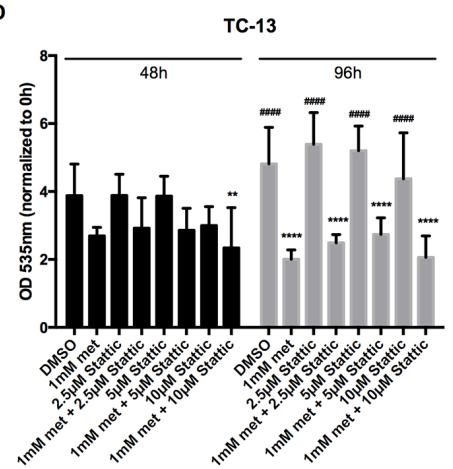

E

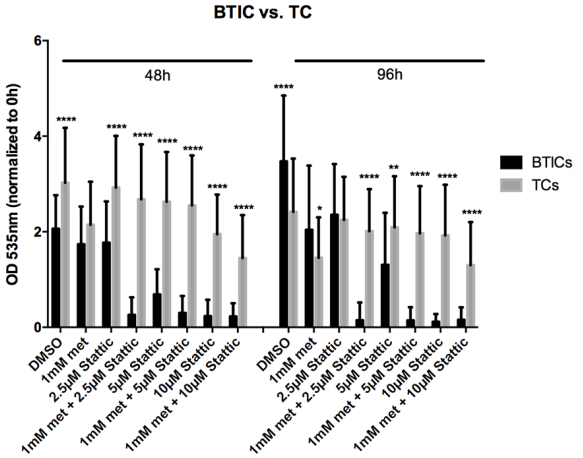

Figure 6: Effects of the combination of Stattic and metformin on proliferation of BTICs and TCs. A, B. Proliferation of BTIC-8 and -13 and C, D. TC-8 and - 13 upon treatment with $1 \mathrm{mM}$ metformin without or with the addition of $2.5,5$ and $10 \mu \mathrm{M}$ Stattic, respectively. E. Proliferation of BTICs (summarized for BTIC-7, $-8,-10,-11,12,-13,-18$ ) was affected significantly more by the combination of metformin and Stattic than of respective TCs (summarized for TC-7, -8, -10, -11, 12, -13, -18). Asterisks indicate significant differences as compared to the corresponding DMSO-control, the pound signs indicate significance as compared to $1 \mathrm{mM}$ metformin. 
overexpressing cells however remained only moderate, which might either be explained by insufficient functioning of the constitutively active from of STAT3 or by Stattic not being fully specific for the inhibition of the Tyr705 phosphorylation site.

In line with our observations for Stattic, we observed a similar decrease in STAT3-phosphorylation under metformin treatment. Also, combined treatment with metformin and Stattic led to additive effects and STAT3 knock-in partly abrogated the effects of metformin.

Metformin is an approved and well-tolerated drug for the treatment of type 2 diabetes [37]. In addition, metformin was proven to inhibit proliferation $[17,19,22$, $38,39]$ and invasion [40], to induce apoptosis [22, 38, 39] and autophagy [38], and to cause differentiation [18] of glioma cells. The underlying molecular mechanisms include inhibition of mTOR by AMPK-dependent and independent ways and inhibition of Akt signaling [22, 38,
41]. In contrast to Stattic, metformin's action on tumor cells is not limited to STAT3 inhibition. Multi-pathway inhibitory agents, such as metformin, may reduce the risk to induce resistance against therapy and may be more efficient than both specific inhibition of the EGFR/STAT3 and mTOR singaling pathways [42]. Effects of metformin on STAT3 have been described in non-malignant [4353] and malignant tissues [23, 24, 54-64], with mainly inhibitory effects of metformin on STAT3-phosphorylation [23, 24, 43, 46-64]. However, one study also reported an increased level of STAT3 in the hypothalamus after metformin treatment [45] and two studies did not find a significant effect of metformin on STAT3 in brown adipocytes [44] and astroglial cells [65]. Only one prior study investigated STAT3 after metformin treatment in glioblastoma and observed a reduced phosphorylation at the Y705 binding site, but the results were merely based on two established glioma cell lines [24]. Our study
A

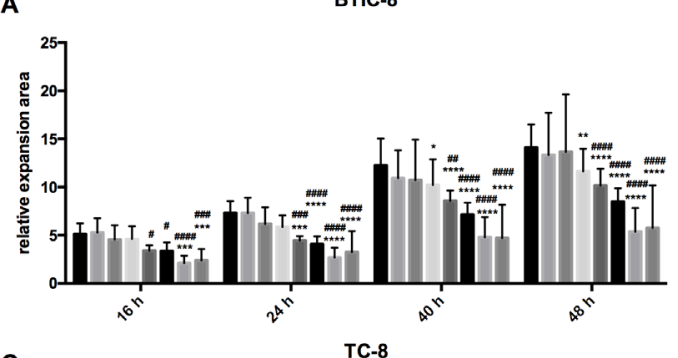

C

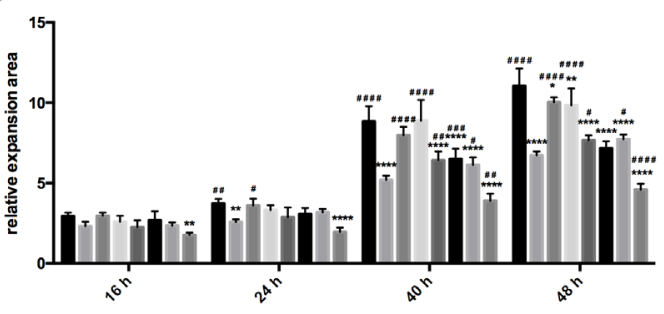

B

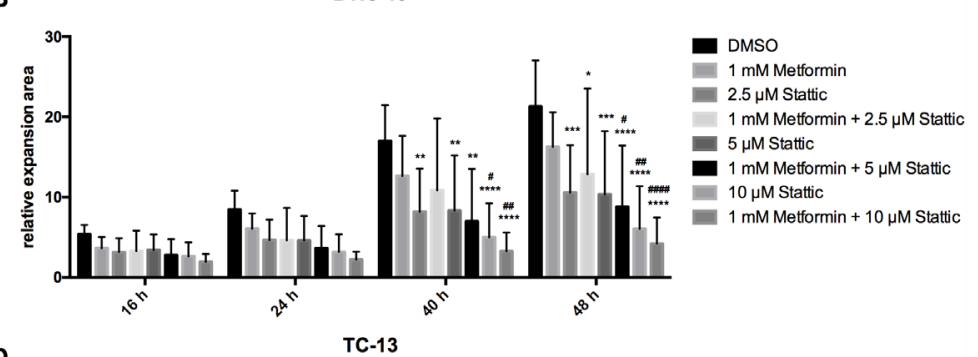

D

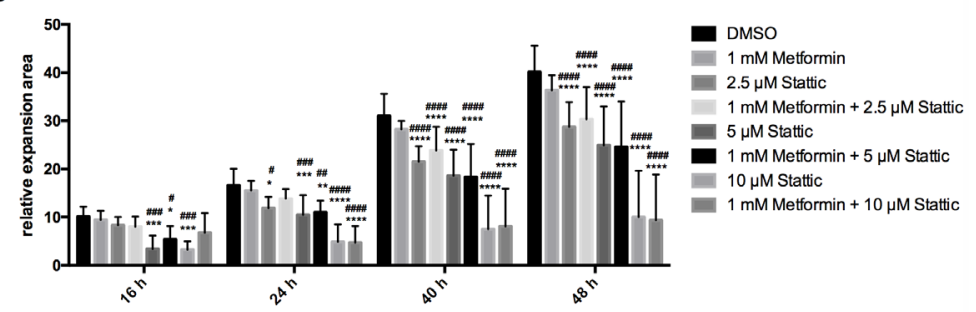

E

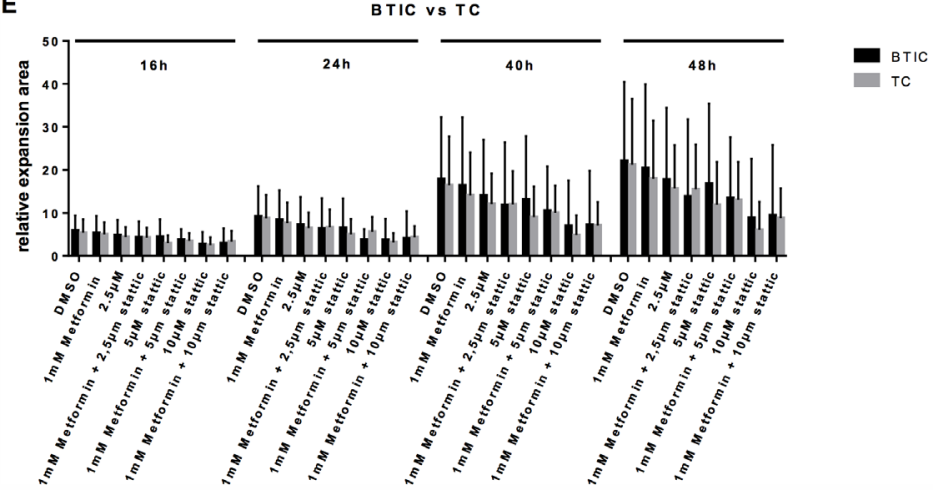

Figure 7: Effects of the combination of Stattic and metformin on migration of BTICs and TCs. A, B. Migration of BTIC-8 and -13 and C, D. TC-8 and -13 upon treatment with $1 \mathrm{mM}$ metformin without or with the addition of $2.5,5$ and $10 \mu \mathrm{M}$ Stattic, respectively. E. Migration of BTICs (summarized for BTIC-7, -8, -10, -11, 12, -13, -18) was not significantly more affected by the combination of metformin and Stattic than that of respective TCs (summarized for TC-7, -8, -10, -11, 12, -13, -18). Asterisks indicate significant differences as compared to the corresponding DMSO-control, the pound signs indicate significance as compared to $1 \mathrm{mM}$ metformin. 
confirmed those first findings in a number of primary BTICs and TCs [23, 24, 54-64], which is closer to the in vivo situation.

The exact mechanism, how metformin inhibits phosphorylation of STAT3 has not been fully elucidated yet. Although AMPK has been discussed as a mediator between metformin and STAT3 signaling in prior studies [59], other authors proposed also AMPK-independent effects of metformin on STAT3 signaling [56]. In addition, mTOR was shown to associate with STAT3 and to facilitate STAT3 activation via specific mTORdependent phosphorylation at Ser727 [66]. Knowing that metformin inhibits activation of mTOR, this may be an additional mechanism explaining the observed effects and is supported by the fact, that the mTOR inhibitor rapamycin also reduces STAT activation [66]. We did, however, also observe reduced phosphorylation at Y705, which may not be explained by the same, but possibly a similar, yet undescribed, mechanism. For some BTICs and TCs, metformin and Stattic treatment also reduced levels of total STAT3 at high doses. Possibly, functional inactivation of STAT3 by metformin or Stattic may also lead to increased degradation of the total protein with increasing doses.

STAT3 is known to mediate a metabolic switch from oxidative phosphorylation to increased glycolysis [67]. STAT3 inhibition by Stattic therefore reduces STAT3-induced glycolysis and metformin inhibits complex 1 of the respiratory chain. This might represent an additional mechanism, explaining additive effects. Additive effects of pharmacological partners of metformin are highly desirable, as metformin was mostly used in higher doses than usually reached in diabetes treatment in most of the prior studies (among others $[17,38])$. The combination of metformin and Stattic therefore allows a reduction of drug doses of the single agents, thereby possibly reducing side effects by maintaining inhibitory effects on tumor cells. However, although metformin was administered at about $10 \%$ of the dose used in other studies on glioma cells [17], drug dosing still needs to be intensified in comparison to the usual antidiabetic drug doses to reach concentrations of $1 \mathrm{mM}$ in brain tissue [68].

To date, only a few specific STAT3 inhibitors, but not Stattic, have been translated to clinical trials. For instance, OPB-31121, which specifically inhibits STAT3phosphorylation was recently investigated in patients with advanced solid tumors (but not brain tumors) in a phase I trial [69] and showed the potential to stabilize $(\mathrm{n}=8)$ or reduce $(\mathrm{n}=2)$ tumors $(\mathrm{n}=18)$.

In summary, combining specific STAT3 inhibition with the well tolerated and approved drug metformin may represent a promising new strategy for the treatment of high-grade glioma, but pharmacokinetic aspects, such as drug delivery to the brain and clinically achievable drug doses still need to be clarified.

\section{MATERIALS AND METHODS}

\section{Ethics statement}

The local department of neuropathology determined the patients' diagnoses and WHO grade, and routine histopathology was accompanied by testing for IDH 1 mutation (by Sanger- or pyrosequencing) and MGMT promoter methylation status (by MethyQESD [70]). Clinical parameters such as age, gender, type of treatment, and overall survival (according to the RANO criteria) were available for all patients. The ethics committee of the University of Regensburg, Regensburg, Germany ( $\mathrm{No}^{\circ} 11-$ 103-0182) approved the study and all patients gave written informed consent.

\section{Tumor cell lines}

BTIC $-7,-8,-10,-11,-12,-13$, and -18 are primary tumor cell cultures derived from resected human glioblastoma as described before [19, 25]. For enrichment of BTICs, tumor specimens were mechanically (and partly also enzymatically) dissociated, washed with PBS and passed through a cell strainer with $30-\mu \mathrm{m}$ pore size to obtain a single cell suspension (BD, \#352235). Tumor cells were maintained in RHB-A based serum-free culture media (Takara, \#Y40001), supplemented with $20 \mathrm{ng} / \mathrm{ml}$ of the mitogens EGF (\#130097751) and bFGF (\#130093842) (both Miltenyi Biotech), at $37{ }^{\circ} \mathrm{C}, 5 \% \mathrm{CO}_{2}, 95 \%$ humidity in a standard tissue culture incubator. Progenitor features of BTIC lines were verified by clonogenicity assays, and partly by tumor take assays in an immunocompromised mouse model. Differentiated TCs were generated via exposure of BTICs to $10 \%$ FBS (Biochrom, \#S0115) in DMEM (\#D6046) supplemented with $50 \mathrm{U}(\mathrm{v} / \mathrm{v})$ Penicillin, 0.05\% (v/v) Streptomycin (\#P4333), $2 \mathrm{mM}$ (v/v) L-Glutamine (\#G7513), 1\% (v/v) MEM Vitamin Solution (\#M6895) and 1\% (v/v) non-essential amino acids (\#M7145) (all Sigma-Aldrich) for at least 14 days.

\section{Proliferation assay}

As described before [71], proliferation was assessed according to the manufacturers' protocol by CyQUANT ${ }^{\circledR}$ Direct Cell Proliferation Assay (Thermo Scientific, \#C35012). Briefly, cells were seeded considering their stereotypic growing characteristics in different amounts, i.e. at densities of $2.5,3.75$ and $5 \times 10^{4}$ cells/ $\mathrm{ml}$, respectively, in $100 \mu \mathrm{l} /$ well. Non-adherent cells were seeded on laminin- (Corning, \#354 232) coated wells and incubated for $4 \mathrm{~h} .72 \mathrm{~h}$ later the media was renewed and cell triplicates treated with specific concentrations of metformin, Stattic or a combination of both. $100 \mu \mathrm{l} /$ well CyQuant Direct Solution were applied $1 \mathrm{~h}$ prior to measurement (excitation: $480 \mathrm{~nm}$, emission: $535 \mathrm{~nm}$ ). Proliferation was measured at the start of the assay $(0 \mathrm{~h})$, 
and at 48 and $96 \mathrm{~h}$ respectively. Blank values measured at every time point ( $100 \mu \mathrm{l}$ media) and serial cell number dilutions served as references. For all assays, background fluorescence was subtracted and values were normalized to $0 \mathrm{~h}$. Assays were performed in triplicates and repeated twice.

\section{Migration assay}

Tumor spheroids were generated by seeding $5 \mathrm{x}$ $10^{3}$ cells onto agarose-coated wells ( $1 \%$ agarose in $1 \mathrm{x}$ PBS) as described [19, 25, 71]. Cells were cultured for $48 \mathrm{~h}$ to allow spheroid formation. Mature spheroids were transferred into non-coated 96-well plates containing the corresponding drugs. Cell migration was monitored at 0 , $16,24,40$ and $48 \mathrm{~h}$, taking into account the earliest time point when migration was measurable to prevent dilution of results by proliferation effects. The area covered by cells was measured manually (ImageJ software, NIH, USA) by an investigator. Assays were performed in triplicates and repeated twice.

\section{Organotypic brain slice cultures (OBSC)}

OBSC were prepared according to Gogolla et al. [72] with customized modifications. Briefly, rat pups (postnatal day 12) obtained from an in-house facility (Long-Ewans, Sprague Dawley or Wistar) were killed by cervical dislocation and used to obtain OBSCs, as described [19].

$48 \mathrm{~h}$ prior to implantation, lentivirally transduced BTICs were seeded onto agarose coated 96-well plates (10,000 cells/well) to allow for spheroid formation. BTIC-13, BTIC-12 and BTIC-10 were lentivirally transduced using a U57 pHR SFFV GFP plasmid while BTIC-8 was transduced with pLenti-H1-(shRNA-Negcontrol)-Rsv(RFP-Bsd). One spheroid per hemisphere was placed onto the lateral ventricle, facing the hippocampal formation. Cell culture medium, also when containing different treatments, was changed every other day.

In order to monitor spheroid migration, implanted spheroids were visualized at 5-fold magnification under a fluorescent microscope (Zeiss Axio Observer.Z1, Visitron Systems GmbH, \#3834003816) once a week. Several pictures of one infiltration site were merged when necessary using Pixelmator software, version 3.3.2.

\section{Protein isolation and western blot}

To investigate protein levels of (p)STAT3, (p) mTOR, (p)AMPK, or GAPDH, whole-cell lysates were prepared with RIPA buffer (Perbio, \#78440). For Western blot analysis, $30 \mu \mathrm{g}$ of total cell lysates were diluted in Laemmli buffer, separated on a 10\% SDS-PAGE gel and transferred to nitrocellulose membranes by semidry blotting. The membranes were blocked with 5\% milk powder or $5 \%$ BSA in $0.02 \%$ Tween in TBS for 1 h. Membranes were incubated with specific monoclonal antibodies for STAT3 (\#9145), pSTAT3 (phosphorylation site Y705, \#9132 and S727, \#9134), mTOR (\#2983), pmTOR (phosphorylation site Ser2448, \#5536), AMPK (\#2603), pAMPK (phosphorylation site Thr172, \#2535), all from Cell Signaling), or GAPDH (\#sc-48167, Santa-Cruz) overnight at $4^{\circ} \mathrm{C}$. Immunocomplexes were visualized using horseradish peroxidase-conjugated antibodies (goat anti-rabbit, Advansta \#R-05072-500), donkey anti-goat (Santa-Cruz, \#sc-2020)) followed by enhanced chemoluminescence (Western Bright Sirius ECL, Biozym \#541-021). All Western blots were performed in duplicate. If several GAPDH controls are presented, the corresponding pairs are indicated by the same number of asterisks/pounds signs. Several GAPDH bands occurred, if we diluted not only $1 \mathrm{x}(30 \mu \mathrm{g})$ but $2 \mathrm{x}$ $(60 \mu \mathrm{g})$ or more of the total cell lysates in Laemmli buffer and put the same sequence of cell lysates 2- times or more on the gel to reduce the number of stripping steps to evaluate several antibodies with similar molecular weight.

\section{RNA isolation and quantitative real time PCR (qRT-PCR)}

For RNA isolation, cells were incubated in 6-well plates $\left(2 \times 10^{5}\right.$ cells per $\left.2 \mathrm{ml}\right)$. Total RNA was isolated by use of the Nucleo Spin RNA Plus Kit (Macherey-Nagel, \#740 984.25) according to the manufacturer's instructions. Reverse transcription was performed with the Reverse Transcription System (Promega, \#A3500) according to the manufacturer's protocol.

Quantification of STAT3 (forward: 5'-AAA GCA GCAAAG AAG GAG GC-3', reverse: 5'-CTG GCC GAC AAT ACT TTC CG-3') mRNA expression was performed by real-time PCR (Mx3000P Quantitative PCR [qPCR] System, Stratagene) based on SYBR-Green I fluorescence (Brilliant III Ultra Fast SYBR GREEN QPCR Master Mix, Agilent Technologies, \#600883) using the $\Delta \Delta C$ T-method. RPLPO (large ribosomal protein) (forward: 5'-CTG TCT GCA GAT TGG CTA CCC-3', reverse: 5'-GAT GGA TCA GCC AAG AAG GC-3') served as housekeeping gene. Annealing temperatures were optimized for each primer pair. Three serial fivefold dilutions of cDNA, a mixture of all used cDNA-samples, were amplified in duplicates to construct standard curves for both the target gene and the reference (RPLPO, ribosomal protein, large, P0). cDNAsamples of BTICs were diluted 1:10. All samples were used in triplicates. For each reaction, melting curves were used to verify the identity of the amplification products. The target gene amount was divided by the reference (RPLPO) amount. Each of the experimental normalized values was divided by the normalized control (untreated) sample value to generate relative expression levels in fold changes 


\section{Stable STAT3 overexpression}

To achieve stable overexpression of STAT3, BTIC8 and BTIC13 were lentivirally transduced with pLentiTet(CMV)-stat3C-Mut-Rsv(GFP-Puro). The plasmid was made according to the publication of Carro et al. [10] and purchased from AMS Biotechnology.

\section{Statistics}

Analyses of significant differences between treatment groups (mean values and SDs) were performed by two-way ANOVA. We used Dunnett's test to control for multiple comparisons. The level of significance was set at $* \mathrm{P}<0.05, * * \mathrm{P}<0.01, * * *<0.001$ and $* * * * \mathrm{P}<0.0001$. Data were analyzed using GraphPad Prism software (version 6, GraphPad Software, USA). In analyses comparing the combination of metformin and Stattic to the single agents, we used the asterisk to indicate significant differences as compared to the corresponding DMSO-control, whereas the pound sign indicates significance as compared to 1 $\mathrm{mM}$ metformin.

\section{ACKNOWLEDGMENTS}

We cordially thank Ina Weig-Meckl and Birgit Jachnik for excellent technical assistance. We thank Prof. Geley (Biocenter, Division of Molecular Pathophysiology, Innsbruck Medical University) for the kind gift of the U57 pHR SFFV GFP plasmid.

\section{CONFLICTS OF INTEREST}

The authors declare no conflicts of interest.

\section{FUNDING}

This study was supported by the German Research Foundation (KFO262-P10, to C.S.).

\section{REFERENCES}

1. Ostrom QT, Gittleman H, Fulop J, Liu M, Blanda R, Kromer C, Wolinsky Y, Kruchko C, Barnholtz-Sloan JS. CBTRUS Statistical Report: Primary Brain and Central Nervous System Tumors Diagnosed in the United States in 2008-2012. Neuro-oncology. 2015; 17:iv1-iv62.

2. Stupp R, Mason WP, van den Bent MJ, Weller M, Fisher B, Taphoorn MJ, Belanger K, Brandes AA, Marosi C, Bogdahn U, Curschmann J, Janzer RC, Ludwin SK, et al. Radiotherapy plus concomitant and adjuvant temozolomide for glioblastoma. The New England journal of medicine. 2005; 352:987-96.

3. Stupp R, Hegi ME, Gorlia T, Erridge SC, Perry J, Hong YK, Aldape KD, Lhermitte B, Pietsch T, Grujicic D,
Steinbach JP, Wick W, Tarnawski R, et al. Cilengitide combined with standard treatment for patients with newly diagnosed glioblastoma with methylated MGMT promoter (CENTRIC EORTC 26071-22072 study): a multicentre, randomised, open-label, phase 3 trial. The lancet oncology. 2014; 15:1100-8.

4. Singh SK, Clarke ID, Terasaki M, Bonn VE, Hawkins C, Squire J, Dirks PB. Identification of a cancer stem cell in human brain tumors. Cancer research. 2003; 63:5821-8.

5. Galli R, Binda E, Orfanelli U, Cipelletti B, Gritti A, De Vitis S, Fiocco R, Foroni C, Dimeco F, Vescovi A. Isolation and characterization of tumorigenic, stem-like neural precursors from human glioblastoma. Cancer research. 2004; 64:7011-21.

6. Das S, Srikanth M, Kessler JA. Cancer stem cells and glioma. Nature clinical practice. 2008; 4:427-35.

7. Bromberg J. Stat proteins and oncogenesis. The Journal of clinical investigation. 2002; 109:1139-42.

8. Yuan X, Curtin J, Xiong Y, Liu G, Waschsmann-Hogiu S, Farkas DL, Black KL, Yu JS. Isolation of cancer stem cells from adult glioblastoma multiforme. Oncogene. 2004; 23:9392-400.

9. Spitzner M, Ebner R, Wolff HA, Ghadimi BM, Wienands J, Grade M. STAT3: A Novel Molecular Mediator of Resistance to Chemoradiotherapy. Cancers. 2014; 6:1986-2011.

10. Carro MS, Lim WK, Alvarez MJ, Bollo RJ, Zhao X, Snyder EY, Sulman EP, Anne SL, Doetsch F, Colman H, Lasorella A, Aldape K, Califano A, et al. The transcriptional network for mesenchymal transformation of brain tumours. Nature. 2010; 463:318-25.

11. Sherry MM, Reeves A, Wu JK, Cochran BH. STAT3 is required for proliferation and maintenance of multipotency in glioblastoma stem cells. Stem cells (Dayton, Ohio). 2009; 27:2383-92.

12. Schust J, Sperl B, Hollis A, Mayer TU, Berg T. Stattic: a small-molecule inhibitor of STAT3 activation and dimerization. Chemistry \& biology. 2006; 13:1235-42.

13. McMurray JS. A new small-molecule Stat3 inhibitor. Chemistry \& biology. 2006; 13:1123-4.

14. Goodarzi MO, Bryer-Ash M. Metformin revisited: re-evaluation of its properties and role in the pharmacopoeia of modern antidiabetic agents. Diabetes, obesity \& metabolism. 2005; 7:654-65.

15. Evans JM, Donnelly LA, Emslie-Smith AM, Alessi DR, Morris AD. Metformin and reduced risk of cancer in diabetic patients. BMJ (Clinical research ed. 2005; 330:1304-5.

16. Seliger C, Ricci C, Meier CR, Bodmer M, Jick SS, Bogdahn U, Hau P, Leitzmann MF. Diabetes, use of antidiabetic drugs, and the risk of glioma. Neuro-oncology. 2015.

17. Wurth R, Pattarozzi A, Gatti M, Bajetto A, Corsaro A, Parodi A, Sirito R, Massollo M, Marini C, Zona G, Fenoglio D, Sambuceti G, Filaci G, et al. Metformin selectively 
affects human glioblastoma tumor-initiating cell viability: A role for metformin-induced inhibition of Akt. Cell cycle (Georgetown, Tex. 2012; 12:145-56.

18. Sato A, Sunayama J, Okada M, Watanabe E, Seino S, Shibuya K, Suzuki K, Narita Y, Shibui S, Kayama T, Kitanaka C. Glioma-initiating cell elimination by metformin activation of FOXO3 via AMPK. Stem cells translational medicine. 2013; 1:811-24.

19. Seliger C, Meyer AL, Renner K, Leidgens V, Moeckel S, Jachnik B, Dettmer K, Tischler U, Gerthofer V, Rauer L, Uhl M, Proescholdt M, Bogdahn U, et al. Metformin inhibits proliferation and migration of glioblastoma cells independently of TGF-beta2. Cell cycle (Georgetown, Tex. 2016; 15:1755-66.

20. Sesen J, Dahan P, Scotland SJ, Saland E, Dang VT, Lemarie A, Tyler BM, Brem H, Toulas C, Cohen-Jonathan Moyal E, Sarry JE, Skuli N. Metformin inhibits growth of human glioblastoma cells and enhances therapeutic response. PloS one. 2015; 10:e0123721.

21. Owen MR, Doran E, Halestrap AP. Evidence that metformin exerts its anti-diabetic effects through inhibition of complex 1 of the mitochondrial respiratory chain. The Biochemical journal. 2000; 348 Pt 3:607-14.

22. Yu Z, Zhao G, Xie G, Zhao L, Chen Y, Yu H, Zhang Z, Li C, Li Y. Metformin and temozolomide act synergistically to inhibit growth of glioma cells and glioma stem cells in vitro and in vivo. Oncotarget. 2015; 6:32930-43. doi: 10.18632/ oncotarget.5405.

23. Deng XS, Wang S, Deng A, Liu B, Edgerton SM, Lind SE, Wahdan-Alaswad R, Thor AD. Metformin targets Stat 3 to inhibit cell growth and induce apoptosis in triplenegative breast cancers. Cell cycle (Georgetown, Tex. 2012; 11:367-76.

24. Ferla R, Haspinger E, Surmacz E. Metformin inhibits leptin-induced growth and migration of glioblastoma cells. Oncology letters. 2012; 4:1077-81.

25. Moeckel S, Meyer K, Leukel P, Heudorfer F, Seliger C, Stangl C, Bogdahn U, Proescholdt M, Brawanski A, Vollmann-Zwerenz A, Riemenschneider MJ, Bosserhoff AK, Spang R, et al. Response-predictive gene expression profiling of glioma progenitor cells in vitro. PloS one. 2014; 9:e108632.

26. Bromberg JF. Activation of STAT proteins and growth control. Bioessays. 2001; 23:161-9.

27. Bromberg JF, Wrzeszczynska MH, Devgan G, Zhao Y, Pestell RG, Albanese C, Darnell JE, Jr. Stat3 as an oncogene. Cell. 1999; 98:295-303.

28. Lin L, Deangelis S, Foust E, Fuchs J, Li C, Li PK, Schwartz EB, Lesinski GB, Benson D, Lu J, Hoyt D, Lin J. A novel small molecule inhibits STAT3 phosphorylation and DNA binding activity and exhibits potent growth suppressive activity in human cancer cells. Molecular cancer. 2010; $9: 217$.
29. Scuto A, Kujawski M, Kowolik C, Krymskaya L, Wang L, Weiss LM, Digiusto D, Yu H, Forman S, Jove R. STAT3 inhibition is a therapeutic strategy for ABC-like diffuse large B-cell lymphoma. Cancer research. 2011; 71:3182-8.

30. Spitzner M, Roesler B, Bielfeld C, Emons G, Gaedcke J, Wolff HA, Rave-Frank M, Kramer F, Beissbarth T, Kitz J, Wienands J, Ghadimi BM, Ebner R, et al. STAT3 inhibition sensitizes colorectal cancer to chemoradiotherapy in vitro and in vivo. International journal of cancer. 2014; 134:997-1007.

31. Medema JP. Cancer stem cells: the challenges ahead. Nature cell biology. 2013; 15:338-44.

32. Levy DE, Lee CK. What does Stat3 do? The Journal of clinical investigation. 2002; 109:1143-8.

33. Hirano T, Ishihara K, Hibi M. Roles of STAT3 in mediating the cell growth, differentiation and survival signals relayed through the IL-6 family of cytokine receptors. Oncogene. 2000; 19:2548-56.

34. Shinojima N, Tada K, Shiraishi S, Kamiryo T, Kochi M, Nakamura H, Makino K, Saya H, Hirano H, Kuratsu J, Oka K, Ishimaru Y, Ushio Y. Prognostic value of epidermal growth factor receptor in patients with glioblastoma multiforme. Cancer research. 2003; 63:6962-70.

35. Reifenberger G, Collins VP. Pathology and molecular genetics of astrocytic gliomas. Journal of molecular medicine (Berlin, Germany). 2004; 82:656-70.

36. Riemenschneider MJ, Betensky RA, Pasedag SM, Louis DN. AKT activation in human glioblastomas enhances proliferation via TSC2 and S6 kinase signaling. Cancer research. 2006; 66:5618-23.

37. Ferrannini E. The target of metformin in type 2 diabetes. The New England journal of medicine. 2014; 371:1547-8.

38. Gritti M, Wurth R, Angelini M, Barbieri F, Peretti M, Pizzi E, Pattarozzi A, Carra E, Sirito R, Daga A, Curmi PM, Mazzanti M, Florio T. Metformin repositioning as antitumoral agent: selective antiproliferative effects in human glioblastoma stem cells, via inhibition of CLIC1mediated ion current. Oncotarget. 2014; 5:11252-68. doi: 10.18632/oncotarget.2617.

39. Isakovic A, Harhaji L, Stevanovic D, Markovic Z, SumaracDumanovic M, Starcevic V, Micic D, Trajkovic V. Dual antiglioma action of metformin: cell cycle arrest and mitochondria-dependent apoptosis. Cell Mol Life Sci. 2007; 64:1290-302.

40. Gao LB, Tian S, Gao HH, Xu YY. Metformin inhibits glioma cell U251 invasion by downregulation of fibulin-3. Neuroreport. 2013; 24:504-8.

41. Wurth R, Pattarozzi A, Gatti M, Bajetto A, Corsaro A, Parodi A, Sirito R, Massollo M, Marini C, Zona G, Fenoglio D, Sambuceti G, Filaci G, et al. Metformin selectively affects human glioblastoma tumor-initiating cell viability: A role for metformin-induced inhibition of Akt. Cell cycle (Georgetown, Tex. 2013; 12:145-56. 
42. Rao RD, Mladek AC, Lamont JD, Goble JM, Erlichman C, James CD, Sarkaria JN. Disruption of parallel and converging signaling pathways contributes to the synergistic antitumor effects of simultaneous mTOR and EGFR inhibition in GBM cells. Neoplasia (New York, NY. 2005; 7:921-9.

43. McCarty MF. AMPK activation may suppress hepatic production of C-reactive protein by stimulating nitric oxide synthase. Medical hypotheses. 2004; 63:328-33.

44. Klein J, Westphal S, Kraus D, Meier B, Perwitz N, Ott V, Fasshauer M, Klein HH. Metformin inhibits leptin secretion via a mitogen-activated protein kinase signalling pathway in brown adipocytes. The Journal of endocrinology. 2004; 183:299-307.

45. Kim YW, Kim JY, Park YH, Park SY, Won KC, Choi KH, Huh JY, Moon KH. Metformin restores leptin sensitivity in high-fat-fed obese rats with leptin resistance. Diabetes. 2006; 55:716-24.

46. Nerstedt A, Johansson A, Andersson CX, Cansby E, Smith U, Mahlapuu M. AMP-activated protein kinase inhibits IL-6-stimulated inflammatory response in human liver cells by suppressing phosphorylation of signal transducer and activator of transcription 3 (STAT3). Diabetologia. 2010; 53:2406-16.

47. Lv WS, Wen JP, Li L, Sun RX, Wang J, Xian YX, Cao CX, Wang YL, Gao YY. The effect of metformin on food intake and its potential role in hypothalamic regulation in obese diabetic rats. Brain Res. 2012; 1444:11-9.

48. Kim YD, Kim YH, Cho YM, Kim DK, Ahn SW, Lee JM, Chanda D, Shong M, Lee CH, Choi HS. Metformin ameliorates IL-6-induced hepatic insulin resistance via induction of orphan nuclear receptor small heterodimer partner (SHP) in mouse models. Diabetologia. 2012; 55:1482-94.

49. Nerstedt A, Cansby E, Amrutkar M, Smith U, Mahlapuu M. Pharmacological activation of AMPK suppresses inflammatory response evoked by IL-6 signalling in mouse liver and in human hepatocytes. Molecular and cellular endocrinology. 2013; 375:68-78.

50. Lee SY, Lee SH, Yang EJ, Kim EK, Kim JK, Shin DY, Cho ML. Metformin Ameliorates Inflammatory Bowel Disease by Suppression of the STAT3 Signaling Pathway and Regulation of the between Th17/Treg Balance. PloS one. 2015; 10:e0135858.

51. Cansby E, Nerstedt A, Amrutkar M, Duran EN, Smith U, Mahlapuu M. Partial hepatic resistance to IL-6-induced inflammation develops in type 2 diabetic mice, while the anti-inflammatory effect of AMPK is maintained. Molecular and cellular endocrinology. 2014; 393:143-51.

52. Li H, Lee J, He C, Zou MH, Xie Z. Suppression of the mTORC1/STAT3/Notch1 pathway by activated AMPK prevents hepatic insulin resistance induced by excess amino acids. Am J Physiol Endocrinol Metab. 2014; 306:E197-209.

53. Vasamsetti SB, Karnewar S, Kanugula AK, Thatipalli AR, Kumar JM, Kotamraju S. Metformin inhibits monocyte-tomacrophage differentiation via AMPK-mediated inhibition of STAT3 activation: potential role in atherosclerosis. Diabetes. 2014; 64:2028-41.

54. Malki A, Youssef A. Antidiabetic drug metformin induces apoptosis in human MCF breast cancer via targeting ERK signaling. Oncology research. 2011; 19:275-85.

55. Hirsch HA, Iliopoulos D, Struhl K. Metformin inhibits the inflammatory response associated with cellular transformation and cancer stem cell growth. Proceedings of the National Academy of Sciences of the United States of America. 2013; 110:972-7.

56. Lin CC, Yeh HH, Huang WL, Yan JJ, Lai WW, Su WP, Chen HH, Su WC. Metformin enhances cisplatin cytotoxicity by suppressing signal transducer and activator of transcription-3 activity independently of the liver kinase B1-AMP-activated protein kinase pathway. American journal of respiratory cell and molecular biology. 2013; 49:241-50.

57. Incio J, Suboj P, Chin SM, Vardam-Kaur T, Liu H, Hato T, Babykutty S, Chen I, Deshpande V, Jain RK, Fukumura D. Metformin Reduces Desmoplasia in Pancreatic Cancer by Reprogramming Stellate Cells and Tumor-Associated Macrophages. PloS one. 2015; 10:e0141392.

58. Pan Q, Yang GL, Yang JH, Lin SL, Liu N, Liu SS, Liu MY, Zhang LH, Huang YR, Shen RL, Liu Q, Gao JX, Bo JJ. Metformin can block precancerous progression to invasive tumors of bladder through inhibiting STAT3-mediated signaling pathways. J Exp Clin Cancer Res. 2015; 34:77.

59. Yue W, Zheng X, Lin Y, Yang CS, Xu Q, Carpizo D, Huang H, DiPaola RS, Tan XL. Metformin combined with aspirin significantly inhibit pancreatic cancer cell growth in vitro and in vivo by suppressing anti-apoptotic proteins Mcl-1 and Bcl-2. Oncotarget. 2015; 6:21208-24. doi: 10.18632/ oncotarget.4126.

60. Tan XL, Bhattacharyya KK, Dutta SK, Bamlet WR, Rabe KG, Wang E, Smyrk TC, Oberg AL, Petersen GM, Mukhopadhyay D. Metformin suppresses pancreatic tumor growth with inhibition of NFkappaB/STAT3 inflammatory signaling. Pancreas. 2015; 44:636-47.

61. Zhao Z, Cheng X, Wang Y, Han R, Li L, Xiang T, He L, Long H, Zhu B, He Y. Metformin inhibits the IL-6-induced epithelial-mesenchymal transition and lung adenocarcinoma growth and metastasis. PloS one. 2014; 9:e95884.

62. Feng Y, Ke C, Tang Q, Dong H, Zheng X, Lin W, Ke J, Huang J, Yeung SC, Zhang H. Metformin promotes autophagy and apoptosis in esophageal squamous cell carcinoma by downregulating Stat3 signaling. Cell death \& disease. 2014; 5:e1088. 
63. Zhu P, Davis M, Blackwelder AJ, Bachman N, Liu B, Edgerton S, Williams LL, Thor AD, Yang X. Metformin selectively targets tumor-initiating cells in ErbB2overexpressing breast cancer models. Cancer prevention research (Philadelphia, Pa. 2014; 7:199-210.

64. Zhao D, Long XD, Lu TF, Wang T, Zhang WW, Liu YX, Cui XL, Dai HJ, Xue F, Xia Q. Metformin decreases IL-22 secretion to suppress tumor growth in an orthotopic mouse model of hepatocellular carcinoma. International journal of cancer. 2015; 136:2556-65.

65. Zang Y, Yu LF, Pang T, Fang LP, Feng X, Wen TQ, Nan FJ, Feng LY, Li J. AICAR induces astroglial differentiation of neural stem cells via activating the JAK/STAT3 pathway independently of AMP-activated protein kinase. The Journal of biological chemistry. 2008; 283:6201-8.

66. Yokogami K, Wakisaka S, Avruch J, Reeves SA. Serine phosphorylation and maximal activation of STAT3 during CNTF signaling is mediated by the rapamycin target mTOR. Curr Biol. 2000; 10:47-50.

67. Demaria M, Giorgi C, Lebiedzinska M, Esposito G, D'Angeli L, Bartoli A, Gough DJ, Turkson J, Levy DE, Watson CJ, Wieckowski MR, Provero P, Pinton P, et al. A STAT3-mediated metabolic switch is involved in tumour transformation and STAT3 addiction. Aging (Albany NY). 2010; 2:823-42. doi: 10.18632/aging. 100232.

68. Labuzek K, Suchy D, Gabryel B, Bielecka A, Liber S, Okopien B. Quantification of metformin by the HPLC method in brain regions, cerebrospinal fluid and plasma of rats treated with lipopolysaccharide. Pharmacol Rep. 2010; 62:956-65.

69. Oh DY, Lee SH, Han SW, Kim MJ, Kim TM, Kim TY, Heo DS, Yuasa M, Yanagihara Y, Bang YJ. Phase I Study of OPB-31121, an Oral STAT3 Inhibitor, in Patients with Advanced Solid Tumors. Cancer Res Treat. 2015; 47:607-15.

70. Dietmaier W, Lorenz J, Riemenschneider MJ. [Molecular diagnostics in neuropathology]. Der Pathologe. 2015; 36:171-80.

71. Leidgens V, Seliger C, Jachnik B, Welz T, Leukel P, Vollmann-Zwerenz A, Bogdahn U, Kreutz M, Grauer OM, Hau P. Ibuprofen and Diclofenac Restrict Migration and Proliferation of Human Glioma Cells by Distinct Molecular Mechanisms. PloS one. 2015; 10:e0140613.

72. Gogolla N, Galimberti I, DePaola V, Caroni P. Preparation of organotypic hippocampal slice cultures for long-term live imaging. Nature protocols. 2006; 1:1165-71. 